\title{
Toward a Decarceral Sexual Autonomy: Biopolitics and the Compounds of Projected Deviance in Carceral Space
}

\author{
by RAECHEL TIFFE \\ Merrimack College
}

\begin{abstract}
This essay examines the rhetorical and structural divides between the "inside" and "outside" carceral world as they exist within the intersections of racialized state violence and biopolitics. It is also a reflection on my embodied experience, as a volunteer and activist, inside penal and correctional facilities, not in an attempt to center my "freeworld" body as more important than the embodied experiences of incarcerated people, but rather to trouble that binary altogether and to use my experience as a perceived outsider to illuminate what I call the compounds of projected deviance. I will use my experiences working in jails as well as my experiences teaching yoga in an addiction correctional facility to argue for prison abolition and transformative justice, particularly in relation to resettlement. Drawing on the work of prison and queer studies, I argue that space, race, and sexuality interlock in significant ways in historical and contemporary prisons and jails. I will also use my reflections to argue that the feminist project of sexual liberation and autonomy must start with a rejection of sexual Othering for the most marginalized members of society: incarcerated people.
\end{abstract}

Keywords: Carceral space; biopolitics; affect; deviance; queer

\section{"I feel, therefore I can be free".- Audre Lorde}

The first and most emphasized instruction I received upon doing my first workshop in an urban jail in the United States ${ }^{1}$ was in regard to the clothes I should wear: not too tight, not too baggy. Pants or a long skirt. Closed-toe shoes and no hats or bandanas. Preferably no makeup. And under no circumstances was I to touch the inmates.

I followed these directions as best I could and on my first day of doing a group volunteer writing project inside the Hennepin County Juvenile Jail, I wore the loosest jeans I owned and a t-shirt. No makeup. Winter boots. I felt the eyes of the guards on me, and did the work so many women know how to do to deactivate triggers of past sexual violence. They had to look at my body, after all, for my own protection. They had to make sure I wasn't putting myself in danger through the clothes I was wearing in front of the inmates. At least, that was the "logic" I was given by the workshop coordinator, a self-proclaimed feminist man who would, later that day, write me an email berating me for wearing jeans that "hugged my hips" and "tempted" the inmates. When I later started a yoga program in the same jail, numerous people warned me to "be careful" wearing yoga clothes around the boys. Throughout the following year of the yoga program, I was told to strictly self-monitor my clothing choices and warned not to touch the inmates as I would in other yoga classes (in terms of adjustments for alignment or the common massages provided at the end of class in savasana, the final pose). But every week I taught (in sweats and loose tops), I would always feel relief after getting past the guards, and feel comfortable when sharing space with the prisoners.

I became quickly familiar with this standard approach to doing jail and prison work, and when I explored continuing this work at other locations, I noticed that every jail or prison website had a page reserved for the dress code and behavior, nearly all of them talking about was and wasn't "appropriate." Thus, although my experience was not unique to a yoga program or being a woman, both of those particularities made me disproportionately susceptible to criticism --- from the jail and prison officials --- when I failed to perform (my

Correspondence: Raechel Tiffe, Email: raecheltiffe@gmail.com

(Accepted: 4/13/2017) ISSN: 2387-2306 doi: http://dx.doi.org/10.15845/jper.v4i2.1200

Except where otherwise noted, content on this site is licensed under a Creative Commons Attribution 4.0 International License.

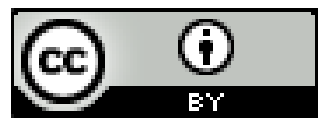


gender? my sexuality?) properly for a carceral setting. The implicit (and sometimes explicit) message from my experience in volunteering in jails and prisons, the Dress Code (and behavior) policies, and general discourse about incarcerated people is that they are always already to be understood as sexually predatory, or at the very least, sexually Other.

This essay examines the rhetorical and structural divides between the "inside" and "outside" carceral world as they exist within the intersections of racialized state violence and biopolitics. It is also a reflection on my embodied experience, as a volunteer and activist, inside penal and correctional facilities, not in an attempt to center my "freeworld" body as more important than the embodied experiences of incarcerated people, but rather to trouble that binary altogether and to use my experience as a perceived outsider to illuminate what I call the compounds of projected deviance. I will use my experiences working in jails as well as my experiences teaching yoga in an addiction correctional facility to argue for prison abolition and transformative justice, particularly as it relates to resettlement. Drawing on the work of prison and queer studies scholars, like Sara Ahmed (2006), Regina Kunzel (2009), and Jay Borchert (2013), I argue that space, race, and sexuality interlock in significant ways in historical and contemporary prisons and jails. I will also use my reflections to argue that the feminist project of sexual liberation and autonomy must start with a rejection of sexual Othering for the most marginalized members of society: incarcerated people.

\section{Method}

My reflections are borne of roughly three years of activism and volunteer work inside of jails and correctional facilities. ${ }^{2}$ I was a writing workshop facilitator at Minnesota's Hennepin County jail for six months before beginning a year-long yoga program at the same location. In Boston, I visited inmates in jails as part of the organization Black \& Pink, and also taught yoga at an addiction rehabilitation facility, both for about a year at the time of publication. The majority of the people at the rehabilitation facility were formerly incarcerated.

At the time of writing, I have been a certified yoga teacher for four years, which provided me the ability and knowledge to facilitate the yoga classes in these spaces. I recorded in a personal journal after nearly every visit, since I was not allowed to bring writing materials into the jail. I use those notes and my memory of these visits to draw on for this essay. This project is not an ethnography, but rather a critical theoretical reflection of activist and volunteer work. ${ }^{1}$

First I will discuss the rules for "decorum" provided by jails and prisoners to any person who wants to visit an inmate. I will expand specifically on the policy about not touching inmates and use my experience as a yoga teacher inside jails to consider the impact of this rule. I also use my experience teaching yoga in non-correctional spaces (corporate yoga studios) to compare and contrast the ways in which I am instructed to approach bodies in any of the spaces. I will then elaborate on my use of the term "compounds of projected deviance" to explain how both discursive and physical frameworks construct prisoners as sexually other and therefore less-than human. Finally, I will put forth a call for a decarceral sexual autonomy as a necessity for restoring humanity and livability to incarcerated and formerly incarcerated people.

\section{Obligatory Warnings: The "Appropriate" Decorum}

As previously mentioned, every jail and prison in the U.S. has policies or guidelines about "appropriate" dress and behavior. Each facility (stated via their webpage) uses different words, but all describe a stance on decorum that Otherizes the inmates "inside" in contrast to the visitors on the "outside." In most cases, the visits are conducted between a plate of glass, with words carried between insiders and outsiders through a telephone. This physical barrier serves as a material reminder of encagement and separation, and is what Megan Comfort (2003) describes as the "border region of the prison where outsiders first enter the institution and come under its gaze" (80). The rules for how to dress and behave appropriately are further in service of delineating between inmate and visitor, and all suggest that danger and disorder loom without visitors' strict adherence to such guidelines.

Foucault refers to this, the kind of management of bodies I've experienced as a visitor and learned about from inmates, as biopolitics. Foucault (1976) writes, 
What we are dealing with in this new technology of power is not exactly society (or at least not the social body, as defined by the jurists), nor is it the individual body. It is a new body, a multiple body, a body with so many heads that, while they might not be infinite in number, cannot necessarily be counted. Biopolitics deals with the population, with the population as a political problem, as a problem that is at once scientific and political, as a biological problem and as power's problem. (p. 245)

Many prison studies scholars take up Foucault, as carceral spaces are clear examples of explicit control of particular populations. However, Foucault (and others) note that social control is not relegated only to the prison, but rather is the foundation of our entire society, both "freeworld" and not. In his reflection on corresponding through letters with a prisoner, Steve Dillon (2011) recounts one letter that described post-prison life on the outside as a limb of, rather than an escape from, the prison walls. Dillon notes, "the prison regime's collusion with heteronormativity and other disciplinary mechanisms made living in the free world virtually indistinguishable from the subjection of incarceration" (p. 176).

The constant surveillance I experience as a woman in the de jure carceral State (i.e., outside) is compounded when I enter the walls of a de facto carceral space, but this boundary is malleable and contingent. For example, surveillance in my predominantly white, middle-income neighborhood means something very different than surveillance in a predominantly Black, low-income community - the former resulting in little interaction with punitive arms of the State, the latter resulting in daily interaction with punitive arms of the State, but all in the name of "decorum." At least in theory, the de jure carceral state is the same across these spaces, but the de facto experience of carcerality blurs and bends across subjects and spaces. These blurred lines and uneven applications or consequences of surveillance enable the justification of (hyper) surveillance-as-protection, in both inside and outside spaces.

As a visitor/volunteer in jails, I have experienced firsthand the surveillance/self-surveillance instigated by the standards of decorum imposed at the Hennepin County and Essex County jails. My white, female-identified and presenting body has been the focal point of slut-shaming and ridicule disguised as "protection." One of the most evident measures of this sexual prey/sexual temptress dichotomy is through the No Contact measures provided on jail websites and also demanded of me by the staff at the jails where I volunteered.

\section{No Human Contact}

The rules about touch in punitive correctional facilities like the jails where I taught were far more draconian than the rehabilitative correction facility. For example, in the jails I was not only told how to dress, but also directed to not touch the inmates, even during yoga, which generally involves teacher-student contact. Being forbidden to touch inmates while teaching yoga is one example of many in a long history of denying touch and/or intimacy to incarcerated people.

In contrast, at the Boston rehabilitation facility where I most recently volunteered, there was no apparent prohibition on touching the patients, and so I followed my typical teaching practice: I asked students at the beginning of every class to use their own agency to determine whether or not they wanted hands-on assists and adjustments during class. No one in the correctional facility opted out of being touched. And so, I used my hands to adjust their poses, align their feet, create length in their spine, and, during savasana (the "corpse pose" at the end of class, at which point you lay on your back completely still), I provided the same head massage that I provide to students when I teach in any other setting.

After one class, a woman named Ronnie thanked me for the massage. Her voice cracked and tears filled her eyes as she explained how powerful it was to feel "nice touch," and that an adjustment to her shoulders helped after years of hunching over in the cold on the streets. I felt grateful to have the opportunity to bring some kindness to this woman, but simultaneously felt deep sadness, recalling all the missed opportunities in which I was forbidden to provide the same for the boys at the juvenile jail. Ronnie had also spent time in jail, as the majority of the patients had. The ability to touch or not touch human beings was arbitrary, based solely on a building location, sometimes with a difference of mere days (i.e., a patient in the rehabilitation facility could have been in jail just the day prior, and yet was treated/regarded significantly differently). 
Whether or not the inmate and visitor are allowed to touch is not always concrete. Currently, there are numerous proposals in jails and prisons across the country for a decrease in physical contact in visiting rooms. Boards that oversee detention center policies suggest that more contact from visitors leads to more exchange of contraband; however, studies show that the majority of contraband found in jails and prisons come from guards, not inmates (Clarke, 2013). While eliminating the allowance of physical touch has an uncertain impact on contraband, it has a concrete impact on inmates' and visitors' mental and emotional well-being (Law, 2015). Ample research reveals that forbidding physical contact with visitors can lead to inmate self-harm, inability to develop positive identities and self-esteem (this has been researched explicitly in relation to incarcerated mothers' ability to touch their children), and decreased ability to adapt to society after release (Kaba, et al., 2014; Aiello \& McQueeny, 2016; Law, 2015). In an interview with writer and prison abolitionist activist Victoria Law, former Rikers Island prisoner Anthony Collado reflects:

Contact visits are like emotional anchors to being human. You can forget to be human when you're not treated as a human... If I couldn't have loving contact with my family and friends, I would have forgotten that I was more than the fights, strip searches and iron bars. I would have chosen violence as my end-all be-all and I would have been lost. (n.p., 2015)

No-contact rules for visitors are dehumanizing. As the countless studies about the injurious impact of solitary confinement suggest, isolating a human being from touch "amount[s] to cruel, inhuman or degrading treatment" (Amnesty International, 2014).

Further, isolation in prison can have long-lasting and irreversible effects on inmates after they are released from prison. Reports of post-traumatic stress disorder (PTSD), and what Terry Gorski (2016) describes as post-incarcerations syndrome (PICS) are of increased likelihood for inmates who experience isolation. Gorski notes,

The effect of releasing this number of prisoners with psychiatric damage from prolonged incarceration can have a number of devastating impacts upon American society including the further devastation of inner city communities and the destabilization of blue-collar and middle class districts unable to reabsorb returning prisoners who are less likely to get jobs, more likely to commit crimes, more likely to disrupt families. (n.p.)

Despite this evidence, physical touch in jails and prisons in the US is considered a "privilege," not a right, and as discussed above, is not guaranteed (Comfort, 2009).

Another form of implementing no-contact visits is to ban in-person visits; that is, not only can visitors not touch inmates, but also they are unable to even be in the same room or space with them. These new rules are justified through an increase of "virtual" jail visits that take place via Skype or other internet video platforms, which also reduce the likelihood of contraband entering jails or prisons. However, no-contact rules are not simply a case of criminal punishment facilities attempting to control contraband, nor are they necessarily a result of cruel intent; rather, like most policies under neoliberalism, these policies are also a matter of profit-motive. According to proponents, video visits reduce contraband and expand visiting hours, but they also reduce the need for and cost of staff (Seville, 2015). Additionally, the video calls bring profit to prisons, as they require inmates or "visitors"/callers to pay for the service, sometimes charging up to $\$ 1 /$ minute (Seville, 2015).

My anecdote about Ronnie in the beginning of this section reiterates the humanizing and healing impact touch can bring, whereas being forbidden to touch the inmates at the detention center concretizes denial of their humanity. This division is deeply connected to the construction of sexual deviance projected onto inmates, as discussed above. More specifically, the denial of touch and humanity is a denial of what Judith Butler describes as a "livable life" granted only to those who fit within sexual normality. Butler (2004) explains that to have a livable life means to be intelligible or made sense of in a way that "laws and culture find you [possible]"; this is a necessity denied to many marginalized bodies, which Butler theorizes through gender non-conforming bodies. Similarly, the incarcerated body is rendered illegible upon confinement — prisoners are not only literally stripped of citizenship (the right to vote, for example), but also deemed unworthy of 
human touch through what I call the compounds of projected deviance. That is, the countless minutiae that develops overtime to articulate the incarcerated body as sexually deviant.

\section{Compounds of Projected Deviance}

I use "compounds" for what it tells us about both the discursive and material constructions that predicate the livability of incarcerated people. Compound can mean a combination of any kind, and it can also refer to "a cluster of buildings having a shared purpose, usually inside a fence or wall." The former, in this case, refers to the ideological messages we receive about incarcerated people through various discursive means. The rhetoric of the hyper-sexual prisoner is a prominent fixture in narrative and journalistic media, and the construction of the criminal as sexually deviant is foundational to the success of mass incarceration. Countless examples reify the (majority brown or Black) prisoner as a sexual menace whose sexuality is more animal than human, and collectively predatory rather than autonomous.

In her thorough research on the history of carceral sexuality, Regina Kunzel (2008) notes "criminality and sexual perversion had long been understood to exist in a tautological relationship, such that attention to one naturally and inevitably invited attention to the other" (p. 7). Kunzel goes on to describe how the early prison functioned as a laboratory for observing and coercing experimentation onto inmates; how sexual identities have been malleable and tenuous in carceral settings; the ways in which the prison has always been understood as a site for sexual perversion and panic-inducing location of homosexual acts; the differences between discourses surrounding sex in men's versus women's prisons, and particularly how these discourses are deeply embedded within racialized logics; and how sexual violence inside prisons has or has not been contended with. Kunzel's work expounds exactly the ways in which the history of the prison has colluded with a history of the social construction of 'inmate as sexual Other.' Perhaps most significant to my experience being warned about (the primarily Black and brown) men in prison is Kunzel's discussion of the racialized construction of prison as a place that is always-already sexually violent. She writes:

While representations of sex in prison have changed in important ways over time, one rhetorical convention has remained strikingly constant, evident from the early nineteenth century and continuing through the early twenty-first. Those who documented sex in prison across this long expanse of time often wrote about the subject as if they were exposing it for the first time... If before [the 1960s] it was difficult to find any substantive discussion of the subject of sexual violence in men's prisons, after the mid-1970s that subject virtually drowned out discussion of anything else. (p. 152)

Indeed, part of the reason that sexual violence became pervasive in cultural understandings of prison life is because structural factors - (like overcrowding, guard abuse, and other inherent dehumanizing factors that compose the fabric of prison life) — made that so. Prison rapes (both between inmates and guard/prisoner rape) were pervasive, and other forms of sexual violence were and continue to be well-documented. But, as Kunzel and other scholars note, occurrences of sexual (mis)conduct are often attributed to the pathology of the prisoner, are rarely contextualized in systemic conditions of the prison itself, and are always defined as inherently violent. This last move in particular denies sexual agency of the prisoner- (a reality in law, after the Prison Rape Elimination Act; prisoners are not granted an ability to consent) - and forecloses any possibility of healthy, consensual, humanizing intimacy (Kunzel, 2008; Borchert, 2016; Page, 2011).

Jay Borchert (2013) writes about the ways in which rules that forbid consensual sex is an explicit means of discrimination against LGBT prisoners, and further dehumanizes all inmates, regardless of sexual orientation. Sexual acts of all kinds are considered crimes in a carceral setting, a result of laws that have deemed prisoners as "vulnerable" and thus incapable of consent. On this Borchert argues,

The logic here is fuzzy. The notion that prisoners somehow lose their individual decision making capabilities when they enter prison in regard to sexual behavior alone is difficult to support. I assume that prisoners retain their, for lack of a better term, rationality while incarcerated aside from prisoners with actual diminished capacity of which there are many. I assume also that coercive and consensual sex takes place in prison just as in society. Finally, I assume that 
prison officials can use the same tools that are used in society to determine if an act is coercive or consensual and that the failure to use these tools, and the category of vulnerable adult... [allows] them to maintain punitive correctional frameworks. (p. 12)

Borchert goes on to explain that prisoners can even be sent to segregation units for being perceived as "potentially dangerous sexual bodies" (p. 10). Here we see how punitive rules about consensual sex are much less about protecting "vulnerable" prisoners, and much more are an extension of power that further denies humanity to incarcerated people. I bring up the historical and contemporary climate of laws surrounding sex in prison to demonstrate the ways in which inmates are always-already sexualized under the law. This is relevant to their treatment while in prison, as well as the treatment they receive at the hands of society after being released from prison. Sexual stigma creates further ostracization and discrimination upon release.

Laws that prevent ex-prisoners from associating with the general population (in housing, jobs, etc.) also contribute to the construction of the incarcerated person as always already sexually deviant. Regina Austin (2004) notes that all of these elements combined result in a deep stigamtization of the incarcerated person. This stigma culminates and intensifies at the intersections of criminality, race, and sexuality. Austin writes that for minority offenders, their race adds to their criminality, as "Black or brown skin...is strongly associated with deviance, particularly sexual depravity, economic irresponsibility, and lawbreaking" (p. 178). Bryan McCann (2012) discusses a similar phenomenon he describes as "the mark of criminality," or "an intricate web of cultural discourses that teach citizens to fear their criminalized neighbors rather than see them as potential allies for building stronger communities" (p. 369-370). The mark of criminality, and the stigma that co-exists along with it, both demonstrate the ways in which incarcerated bodies are interpellated as dangerous, especially sexually dangerous. Anyone who enters the prison - regardless of the non-sexual nature of their work-will be perceived as encountering a potentially threatening sexual situation.

In addition to the ideological functions that construct caged bodies as sexually deviant, my definition of the compounds of projected deviance also refers to the material and physical structures that work in service of the same mission. My work as a yoga teacher in penitentiary spaces has provided me insight into treatment of "inside" and "outside" bodies, and how the physicality of existing in space is crucial in understanding how deviance is concretized in and upon criminally convicted people.

As soon as my body entered the space of the jail, I became both an object to be surveilled and an instrument with which to surveil. As an "outsider" I was provided an ostensible semblance of humanness, in which my body was being objectified and policed as, supposedly, a way to keep me safe from the non-human inmates. However, this act of 'protection' by the State was only a variation of the same sexualization and surveillance applied to the prisoners. By entering the explicitly carceral state, my body became a similarly explicit object of state control. Their actions were to both police me and police the inmates' imagined (sexual) responses, not to 'protect' me. Thus even in the act of apparent protection, my body, once inside the confines of the criminal punishment system (the physical building of the jail), became-even more explicitly than in my "outside" life — an object of State control.

\section{Insider Bodies/Freeworld Bodies}

My body's contingent relationship to space can be understood through what Sara Ahmed (2011) describes as my orientation, or "the point from which the world unfolds: the 'here' of the body, and the 'where' of its dwelling" (p. 151). Outside the prison system, all bodies experience surveillance/self-surveillance and policing. However, some bodies experience them to a greater and more insidious degree than others. As previously noted, my white skin and the neighborhoods in which I most often dwell decrease the likelihood of police surveillance. As a woman, however, I am surveilled to a greater degree in any space I occupy (e.g., on the street, in the classroom, in workplace meetings, etc.). Black and brown bodies experience increased policing in general, but as Ahmed suggests, bodies in relation to particular spaces produce particular orientations that not only impact the body, but provide the conditions for possibility. She writes,

What comes into view, or what is within our horizon, is not a matter of what we find here or there, or even where we find ourselves, as we move here, or there. What is reachable is deter- 
mined precisely by orientations we have already taken. Or we could say that orientations are about the directions we take that put some things and not others in our reach. (p. 152)

Ahmed's discussion of the horizon is useful when thinking about the orientation of bodies within and outside the prison walls.

Within a carceral complex, bodies are literally trapped from particular horizons, from possibilities of "outside." However, as Stephen Dillon (2011) notes, "the free world [is] intimately connected to and constituted by the prison, and...the free world is anything but free; rather, it is an extension of the unfreedom central to the mundane operations of the prison" (p. 170). That is, the orientation of particular bodies-(disproportionately bodies of color, poor bodies, queer bodies) - to the "free world" reveals that the point from which the world unfolds for them never gives way to a space of liberation.

Like Dillon and Ahmed, I understand incarcerated bodies' relation to space as something that perpetuates a specific means of racialization and sexualization, and also illustrates the flawed logic of being "inside" or "outside" the prison system. The boys - all Black and brown-I worked with inside the jail are marked, both inside and outside, as sexually predatory. My body, in contrast, is allowed malleability. A body of target in some spaces, a body of provocation and temptation in another. In the space of the jail, I am both predator and prey. All of my interactions and all of the guidelines I've been provided before entering prison and jail spaces have demonstrated this. No human contact, no short clothes, no see-through clothes, no makeup - my visitor body concretizes the inmates' sexual deviance.

\section{Toward a Decarceral Sexual Autonomy}

... the body implies mortality, vulnerability, agency: the skin and the flesh expose us to the gaze of others but also to touch and to violence. The body can be the agency and instrument of all these as well, or the site where "doing" and "being done to" become equivocal. Although we struggle for rights over our own bodies, the very bodies for which we struggle are not quite ever only our own. The body has its invariably public dimension; constituted as a social phenomenon in the public sphere, my body is mine is not mine. (Butler, 2004, p. 21).

In the passage above, Butler writes of a body that is both "mine and not mine." Indeed, my experience as a free world body in carceral spaces is an exaggerated but apt example of exactly this truth: under white supremacy and capitalism, bodies are not only not-free, but also contingent, limited, and conditional. As sexual beings, then, different bodies are granted different access to humanizing interaction, whether they are sexual or not. As previously discussed, being forbidden to touch inmates was always already about a presumed sexual deviance- despite the fact that touch in yoga is non-sexual.

Given the confines, the limits of freedom on nearly all bodies, how might we stretch toward a possibility of decarceral sexual autonomy? The first answer is very simple (in that it is clear, not that it is easy): abolish prisons. Incarceration precludes autonomy in any form, and thus any such project of liberatory body autonomy would also require a dismantling of systems that create un-free conditions (prisons, capitalism, white supremacy, to name a few).

With the realization that overthrowing the oppressive foundations from which our society has been built is far-off, and in the interest of enabling mildly more livable conditions for all of those who suffer from the confines of the prison system, I conclude this article with an echo of scholars and activists before me who are fighting for a world that humanizes inmates and former inmates, calling on policy and media makers, correctional boards and staff, activists, and educators. First, as Borchert argues, overturning laws that forbid consensual sex in prison will provide agency and also reduce the additional punishments they suffer when violating these nonsensical prohibitions. Second, creating and promoting media that avoids tired tropes about hyper-sexual and/or dangerously sexual prisoners will contribute to the fabric of a cultural imaginary that envisions inmates as sexually autonomous people, rather than predatory animals. Third, changing the draconian visitation rules, allowing consensual touch, and ending the sexualization of the clothing of visitors (especially 
femmes and/or women) can act as material signifiers that prisoners are not animals to be feared.

Finally, those of us invested in sustainable conditions for released inmates looking to resettle in the "freeworld," we must contend with the ways in which discourses of sexual deviance egregiously linger. Conditions for successful resettlement are not only contingent on factors such as housing and jobs (although those things are very important), but also on a commitment to demanding and asserting the humanness - and thus also non-criminalized sexual autonomy_of formerly incarcerated people.

In one of my visits to the jail, I tried to verbally explain a pose to Deqwan, one of the young inmates. "Put your right shoulder over your hip," I said. He still wasn't getting it. "Like this," I demonstrated, with my own body. Still misaligned. The other boys laughed. Deqwan was frustrated and embarrassed. I looked around the room and through the window where a guard occasionally looked on. No one was around. Quickly I put my hands on his shoulder and adjusted him into the correct posture. He got it. A look of accomplishment washed over his face and he smiled as he started to make sense of his own body in the pose. A mere moment of human touch enabled a significant moment of ease in the body.

"Ifeel, therefore I can be free," Audre Lorde writes. She meant feeling in the abstract, (that is to say, to feel an emotion, for example), but I think it applies to feeling the sensory warmth of touch, too. And although true liberation will never exist within a carceral society, the humanization of inmates as bodies --- as people --- worthy of human touch just might bring momentary glimpses of freedom.

\section{References}

Ahmed, S. (2006) Queer Phenomenology: Orientations, Objects, Others. Durham: Duke University Press.

Aiello, B. \& McQueeny, K. (2016) 'How can you live without your kids?' Distancing from and embracing the stigma of 'incarcerated mother', Journal of Prison Education and Reentry, 3(1). doi: http://dx.doi. org/10.15845/jper.v3i1.982

Amnesty International, (2014) Entombed: Isolation in the US Federal Prison System, Amnesty International Ltd., Retrieved from http://www.amnestyusa.org/sites/default/files/amr510402014en.pdf.

Borchert, J. W. (2013-08-09) "Denying Rights The Failure to Extend Lawrence v. Texas to Prisons and Prisoners" Paper presented at the annual meeting of the American Sociological Association Annual Meeting, Hilton New York and Sheraton New York, New York, NY.

Butler, J (2004) Undoing Gender. New York: Routledge.

Clarke, M. (2013) Contraband Smuggling a Problem at Prisons and Jails Nationwide. Prison Legal News. Retrieved from https://www.prisonlegalnews.org/news/2013/jan/15/contraband-smuggling-a-problemat-prisons-and-jails-nationwide/.

Dillon, S. (2011) The only freedom I can see: Imprisoned queer writing and the politics of the unimaginable. In Stanley, E.A. \& Smith, N. (2011). (Eds.). Captive Genders: Trans Embodiment and the Prison Industrial Complex. Oakland: AK Press.

Gorski, T. (2016). Post-Incarceration Syndrome and Relapse, Terry Gorski, Retrieved from https://terrygorski. com/2016/07/29/post-incarceration-syndrome-pics-and-relapse/.

Kunzel, R. (2010) Criminal Intimacy: Prison and the Uneven History of Modern American Sexuality. Chicago IL: University of Chicago Press.

Law, V. (2015) No Touching: Relatives of Rikers Inmates Protest Proposed Visitation Rules, Gothamist. Retrieved from http://gothamist.com/2015/09/09/rikers_physical_contact.php.

Page, J. (2011) The Toughest Beat: Politics, Punishment, and the Prison Officers Union in California. New York, NY: Oxford University Press.

Seville, L.R. (2015) “As Jail Visits Go High-Tech, Isolation Grows,” NBC News. Retrieved from http://www. nbcnews.com/feature/in-plain-sight/jail-visits-go-high-tech-isolation-grows-n313616. 


\section{Endnotes}

${ }^{1}$ The requirements in relation to dress is a largely US phenomenon. It is beyond the scope of this paper to unpack the cultural difference between US and non-US societies (and thus also prisons and jails), but the author is aware that this may seem unusual to some European readers.

${ }^{2}$ I consulted with a member of the IRB committee at the college where I work who believed this reflection would not require the IRB process. All names used are pseudonyms.

Acknowledgements: The author would like to thank the young men at the Hennepin County Detention Center for their openness to the author's visits. The author would also like to thank Melody Hoffmann and Logan Casey for their helpful feedback on earlier versions of this essay.

Raechel Tiffe is a lecturer in Women's and Gender Studies at Merrimack College. 